\title{
Efeito de dois métodos de pastejo rotacionado no controle dos parasitas gastrintestinais e no desenvolvimento ponderal \\ de cordeiros do nascimento ao desmame
}

\section{Effect of two methods on rotational grazing in contorl gastrointestinal parasites and performance in lambs from birth to weaning}

\author{
Hyldeth de Souza ${ }^{1}$; Maria Conceição Zocoller Seno ${ }^{2 *}$; \\ Luís Henrique Fernandes ${ }^{3}$; Walter Veriano Valério Filho ${ }^{4}$
}

Resumo

Estudou-se o efeito de dois métodos de pastejo, um rotacionado e alternado com bovino adulto e o outro rotacionado sem alternância com bovino no controle dos parasitas gastrintestinais e no desenvolvimento ponderal de cordeiros, do nascimento ao desmame. Utilizou-se uma área experimental constituída por três módulos de 1,67 ha cada. Os módulos foram subdivididos em oito piquetes com cerca eletrificada. Cada piquete foi pastejado por cinco dias totalizando 40 dias em cada módulo, durante junho de 2001 a janeiro 2002. No tratamento 1 (T1) foram utilizados dois módulos, o primeiro iniciou com 14 cordeiros e 20 ovelhas e o segundo com 4 bovinos adultos. As trocas de módulos entre ovinos e bovinos foram a cada 40 dias. No tratamento 2 (T2) um terceiro módulo foi usado com 14 cordeiros e 20 ovelhas, também em sistema rotacionado, porém sem a alternância com bovino. A cada 14 dias realizou-se a colheita de fezes para contagem de ovos por grama de fezes (OPG) e coprocultura e a pesagem dos cordeiros. A cada 28 dias colheu-se sangue para exames do volume globular (VG). Os dados de OPG, VG e do peso foram submetidos à análise estatística, utilizando-se o Statistical Analysis System (SAS). Pelos resultados obtidos, verificou-se que os parasitas encontrados nos cordeiros foram Strongyloides, tricostrongilideos do gênero Haemonchus e protozoários do gênero Eimeria. Os gêneros Strongyloides e Eimeria e o VG não apresentaram diferença significativa $(\mathrm{p}>0,01)$ entre os dois tratamentos. No entanto, o método de pastejo rotacionado e alternado com bovino adulto exerceu influência significativa $(p<0,01)$ no controle dos tricostrongilídeos nas faixas etárias de 43-56 dias e 57-70 dias. No desenvolvimento ponderal, os pesos médios ao desmame foram de $31,53 \mathrm{~kg}$ no $\mathrm{T} 1$, e $30 \mathrm{~kg}$ no T2 e não se verificou diferença estatística significativa $(\mathrm{p}>0,05)$ entre os dois tratamentos.

Palavras-chave: Cordeiros, parasitas gastrintestinais, pastejo alternado, pastejo rotacionado

1 Médica Veterinária, Mestre em Zootecnia, Sistema de Produção Animal, FEIS/UNESP, Campus Ilha Solteira -SP; e-mail: hyldeth@bol.com.br, Rua General Osório, 249, Apto 202, CEP: 19020-630, Presidente. Prudente/SP

2 Prof $^{\text {a }}$ Adjunta do Departamento de Biologia e Zootecnia da FEIS/UNESP, Campus Ilha Solteira/SP

3 Mestre em Zootecnia pela FEIS/UNESP, Campus Ilha Solteira /SP

4 Prof. Assistente Doutor do Departamento de Matemática da FEIS/UNESP, Campus Ilha Solteira

* Autor para correspondência 


\begin{abstract}
The effects of two methods of rotational and grazing involving cattle and sheep on the control of gastrointestinal parasites and performance in lambs from birth to weaning were evaluated. Three areas with 1, 67 ha were sub-divided by electric fence into eight paddocks. Each paddock was grazed for 5 days and rested 35 days through June/01 to January/ 02. In treatment 1, 14 lambs and 20 ewes grazed in area 1 while 4 adults' bovines grazed in area 2 . After 40 days the animals inverted areas, that is, lambs and ewes grazed in area 2 and steers in area 1. At the same time in treatment 2, 14 lambs and 20 ewes were kept in area 3 under a simple rotational grazing system. Nematode egg counts (FEC) and larval culture were determined from fecal samples and live weight was obtained each 14 days. Packed cell volume (PCV) was determined every 28 days from blood samples. Data of FEC, PCV and live weight were statistically analyzed using the Statistical Analysis System (SAS). The parasites found in lambs were, Haemonchus and protozoa Eimeria spp. The genera Strongyloides and Eimeria and PCV there were not difference statistical between treatments $(p<0,01)$. The alternated grazing method between sheep and cattle reduced the parasitic infection $(\mathrm{p}<0,01)$ of Haemonchus in ages 43-56 days and 57-70 days. The average lamb weights were: $31,53 \mathrm{~kg}$ in T1 and $30 \mathrm{~kg}$ in T2 and there were no statistical difference between treatments $(\mathrm{p}<0,05)$ on lamb performance
\end{abstract}

Key words: Lambs. Gastrointestinal parasites, grazing alternated, grazing rotation

\section{Introdução}

Um dos obstáculos à criação de ovinos é a sua suscetibilidade aos endoparasitas, principalmente os nematódeos gastrintestinais, que afetam negativamente a criação.

Os ovinos, dentre os animais domésticos, são os mais acometidos por endoparasitas gastrintestinais, hepáticos e pulmonares durante toda a sua vida produtiva. Segundo Echevarria (1986), as perdas na produção de ovinos variam, basicamente, em função das condições climáticas, do grau e do tipo de parasitismo, da resistência imunitária do animal, da taxa de lotação e da faixa etária.

$\mathrm{Na}$ ovinocultura, as categorias mais susceptíveis aos efeitos do parasitismo são os cordeiros desmamados e as ovelhas no final da gestação e durante a lactação ("fenômeno periparto"), quando ocorre uma depressão do sistema imunológico (AMARANTE et al., 1992). Alguns trabalhos têm mencionado que os problemas com verminose em cordeiros começam realmente a surgir após o desmame, quando então há a preocupação de mantêlos com baixa infecção parasitária. No entanto, os cordeiros, na faixa etária antes do desmame (8 a 10 semanas de idade) já apresentam uma carga parasitária, sendo detectada infecção patente por helmintos (ROCHA, 2003) e protozoários do gênero Eimeria (AMARANTE, 2001). De acordo com Macedo et al.(1997), cordeiros mantidos em pastagens do nascimento ao desmame apresentam um nível baixo de infecção endoparasitária até oito a 10 semanas de vida; a partir da $10^{\mathrm{a}}$ semana, essa infecção já é considerável, tornando-se intensa na $14^{\mathrm{a}}$ semana. Cordeiros jovens, criados em pastejo no período de amamentação, estão expostos à contaminação por larvas infectantes $\left(\mathrm{L}_{3}\right)$ eclodidas de ovos de nematódeos provenientes das fezes de suas mães. Rocha (2003), comparou a resistência de cordeiros das raças Santa Inês e Ile de France, criados em pastejo, com suas mães, do nascimento ao desmame, e verificou que a maioria dos cordeiros Ile de France necessitou de medicação anti-helmíntica aos 43 dias de idade e os cordeiros Santa Inês aos 57 dias.

Quanto aos helmintos que mais acometem os ruminantes, Amarante e Barbosa (1995) constataram que os gêneros de helmintos de maior ocorrência na região de Botucatu, SP, foram Haemonchus spp. seguido por Trichostrongylus spp., Cooperia spp., Oesophagostomum spp. e Strongyloides papillosus, acometendo bovinos e ovinos adultos; e Haemonchus spp., Oesophagostomum spp. e Trichostrongylus spp. acometendo cordeiros antes do desmame, o que foi confirmado por Rocha (2003). 
É comum nos criadores adotarem como única medida de controle das parasitoses a utilização intensiva e incorreta de anti-helmínticos, o que contribui para o surgimento de populações de parasitas resistentes (AMARANTE et al., 1992) quase que inviabilizando o seu controle químico. Isso tem levado à procura de medidas alternativas de controle, quer com a seleção de animais geneticamente resistentes aos parasitas e/ou a seleção de animais resistentes dentro de raças ou com o manejo das pastagens visando a sua descontaminação. Com o objetivo de se prevenir e/ ou diminuir a contaminação das pastagens, uma vez que menos de $5 \%$ da população parasitária encontrase dentro dos animais e $95 \%$ no pasto, tem-se utilizado o pastejo alternado de ovinos com bovinos (PINHEIRO; ECHEVARRIA; ALVES-BRANCO, 1983; FERNANDES et al., 2004) ou eqüinos adultos (BAGNOLA JÚNIOR; AMARANTE; MEYER, 1996). Desta forma, as larvas infectantes parasitas que acometem os ovinos, ao serem ingeridas pelos animais adultos de outras espécies, são destruídas, por não encontrarem um ambiente favorável para o seu desenvolvimento.

O presente trabalho teve como objetivo verificar o efeito de dois métodos de pastejo rotacionado, alternado com e sem bovino adulto, no controle dos parasitas gastrintestinais e no desenvolvimento ponderal de cordeiros, do nascimento ao desmame.

\section{Material e Métodos}

O experimento foi realizado na Fazenda de Ensino e Pesquisa (Pomar) da UNESP - Campus de Ilha Solteira, SP, e as análises laboratoriais no Laboratório de Parasitologia do Departamento de Biologia e Zootecnia - FEIS/UNESP, com início em 05 de Junho de 2001 e conclusão em 07 de Janeiro de 2002. Foram utilizados 28 cordeiros da raça Ile de France, do nascimento ao desmame, nascidos de mães primíparas cruzas Ile de France, com idade em torno de 16 meses (dois dentes) e oriundas do município de Tupi Paulista, SP, e entre dois e quatro bovinos adultos, com idade acima de dois anos e meio, castrados, da raça Guzerá, pertencentes à Fazenda Experimental da UNESP - Campus de Ilha Solteira, município de Selvíria, MS. Esses animais foram tratados previamente com moxidectina $(0,20 \mathrm{mg} / \mathrm{kg}$, Cydectinâ, Fort Dodge). No período seco do ano foram utilizados dois bovinos.

Os cordeiros foram pesados ao nascimento e cada 14 dias até os 90 dias de idade (desmame). Foram adotadas todas as medidas de manejo sanitário preconizado para cordeiros recém-nascidos, tais como corte e desinfecção do umbigo com tintura de iodo, caudectomia com anéis de látex nas fêmeas e vacinação contra clostridioses na ocasião do desmame. A área experimental total foi de 5,01 ha, formada por Panicum maximum, dividida em três módulos de 1,67 ha cada. Os módulos foram subdivididos em oito piquetes cada um, com cerca interna eletrificada, com sombra artificial, bebedouro e comedouro (Figura 1). No primeiro e segundo módulos pastejaram alternadamente os ovinos e os bovinos; e no terceiro módulo ficaram apenas os ovinos. Os animais permaneceram por cinco dias em cada piquete, num sistema rotacionado e alternado, no primeiro e segundo módulos, com descanso de 35 dias em cada módulo. A cada 40 dias, os ovinos eram transferidos para o módulo dos bovinos e vice-versa, totalizando 80 dias para os animais retornarem ao piquete inicial. No terceiro módulo, os ovinos foram manejados num método rotacionado, sem a utilização de bovinos. Os cordeiros permaneceram até o desmame nos piquetes com suas mães, e a partir dos 10 dias de idade, eles passaram a receber uma suplementação alimentar no sistema de "creepfeeding" para irem se acostumando com o feno e o concentrado. A ração foi colocada no cocho dos cordeiros "ad libitum", numa quantidade de consumo estimado entre $100 \mathrm{~g}$ e $200 \mathrm{~g} / \mathrm{animal} / \mathrm{dia}$, com aproximadamente $18 \%$ de $\mathrm{PB}$, como recomendado pelo Agricultural and Food Research Council (1993), contendo milho (70\%), farelo de algodão (15,5\%), farelo de trigo $(10,0 \%)$, uréia $(1,0 \%)$, sal mineral $(1,0 \%)$, sal comum $(1,0 \%)$ e calcário calcítico $(1,5 \%)$. 
O feno utilizado foi de Cynodon dactylon, cv. Coastcross. As amostras fecais foram colhidas a cada 14 dias, de todos os animais, individualmente, da ampola retal, para a realização da contagem de ovos por grama de fezes (OPG), segundo a técnica de Gordon e Whitlock (1939). A coprocultura foi realizada nas mesmas datas, segundo a técnica de Roberts e O’Sullivan (1949), com a extração de larvas pelo método de Baermann (1917) e a identificação dos parasitas de acordo com Keith (1953).

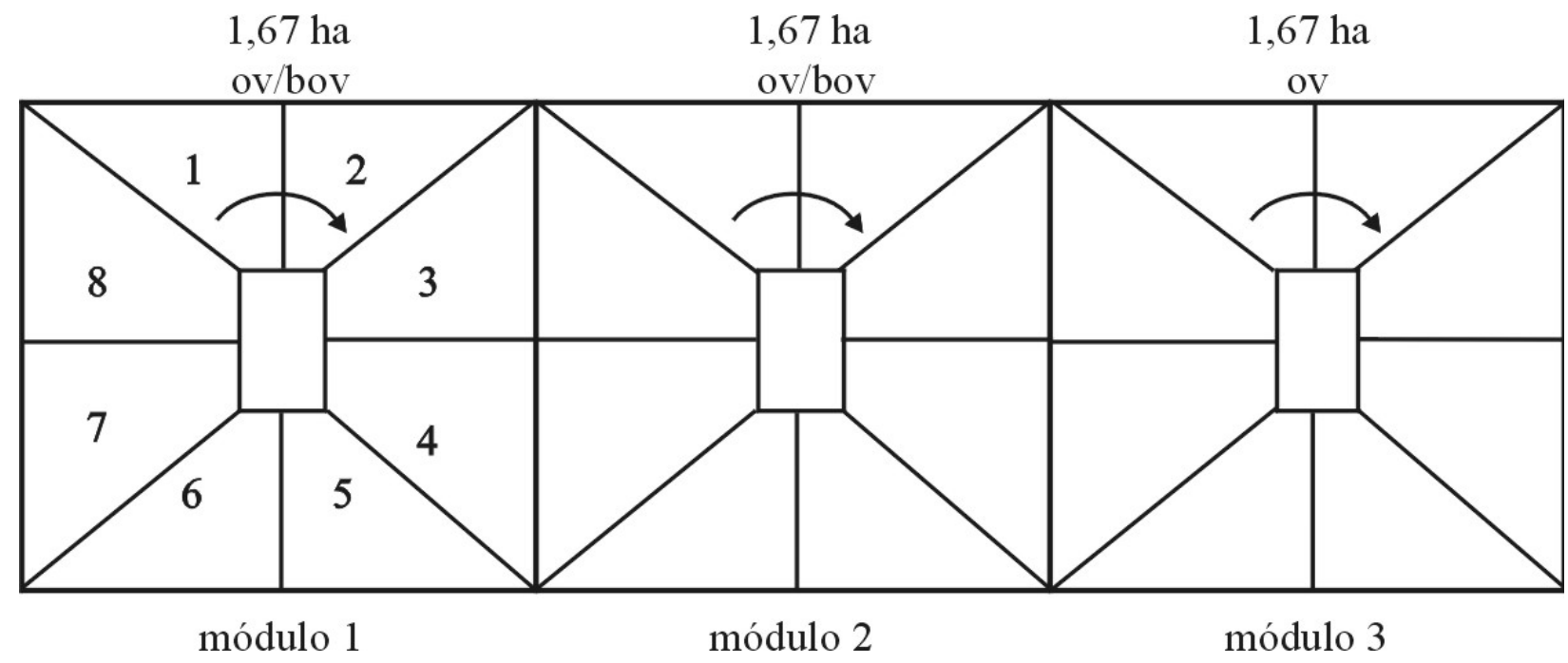

Figura 1- Esquema da área experimental localizada na Fazenda de Ensino e Pesquisa (Pomar). UNESP, município de Ilha Solteira, São Paulo.

As colheitas de sangue foram feitas em frascos tipo "vacutainer" com anticoagulante EDTA a 10\%, por venopunção da jugular, de cada cordeiro, a cada 28 dias, para a determinação do volume globular (VG) pelo método do microhematócrito segundo Ferreira Neto, Viana e Magalhães, (1978).

As desverminações ocorreram a partir de 1.000 OPG para tricostrongilídeos após a realização dos exames coprológicos e hematológicos. Os antihelmínticos utilizados foram o albendazol oral $(10 \mathrm{mg} /$ kg, Valbazenâ, Smithkline \& Cia. Ltda) associado ao levamisol oral (7,5mg/kg, Ripercolâ L 150F, Fort Dodge).

Utilizaram-se dois tratamentos, onde:

Tratamento 1 (T1): constituído por 14 cordeiros e 20 ovelhas em pastejo rotacionado e alternado com quatro bovinos adultos.

Tratamento 2 (T2): constituído por 14cordeiros e 20 ovelhas em pastejo rotacionado.
Adotou-se para as variáveis estudadas (OPG para Strongyloides, OPG para tricostrongilídeos, contagem de oocistos de Eimeria, determinação do VG e do peso), o modelo misto através dos seguintes efeitos: tratamento (1 e 2), animal dentro do tratamento, faixa etária, interação tratamento x faixa etária e o erro, onde os efeitos animal dentro do tratamento e erro são considerados aleatórios e os demais, fixos.

Efetuou-se a correção dos graus de liberdade (GL) para os efeitos faixa etária, interação tratamento x faixa etária e erro através dos critérios: Greenhouse e Geisser (1959) e Huynh e Feldt (1970) utilizandose o procedimento de General Linear Models (GLM) do Statistical Analysis System (SAS). Para o OPG de tricostrongilídeos e Strongyloides sp. e contagem de oocistos de Eimeria spp., houve a necessidade da transformação logarítmica dos dados para posterior aplicação da metodologia anteriormente citada. Para a comparação de médias de tratamentos, utilizou-se o teste de Tukey. 
As faixas etárias adotadas para OPG de Strongyloides, Tricostrongilídeos, Eimeria, e peso corporal foram: $1^{\text {a }}$ faixa de 0 a 14 dias; $2^{\text {a }}$ de 15 a 28 dias; $3^{\mathrm{a}}$ de 29 a 42 dias; $4^{\mathrm{a}}$ de 43 a 56 dias; $5^{\mathrm{a}}$ de 57 a 70 dias; $6^{\text {a }}$ de 71 a 84 dias e $7^{\text {a }}$ de 85 a 98 dias. Para o volume globular foram: $1^{\text {a }}$ faixa de $0-28$ dias; $2^{\mathrm{a}}$ de 29-56 dias e $3^{\text {a }}$ de $57-84$ dias.

\section{Resultados e Discussão}

As Figuras de 2 a 6, apresentam as médias do OPG de helmintos dos gêneros Strongyloides e Haemonchus, contagem de oocistos de Eimeria spp., volume globular e peso corporal dos cordeiros Ile de France, respectivamente, durante o período de experimentação.

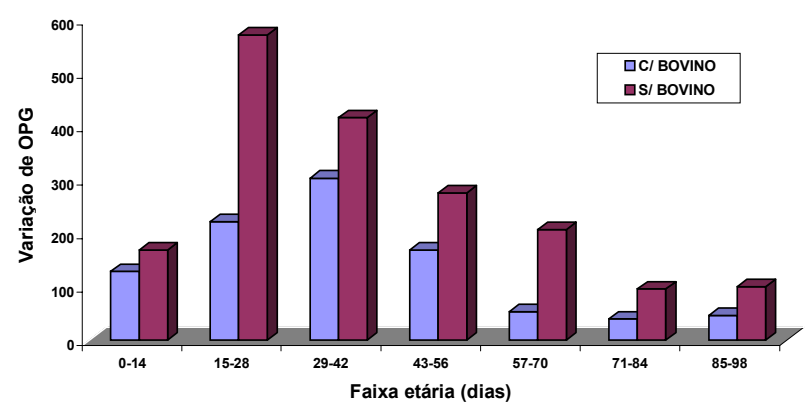

Figura 2- Valores médios de OPG de Strongyloides papillosus em cordeiros Ile de France $(\mathrm{n}=14)$, submetidos a pastejo rotacionado alternado com bovino e sem bovino. Ilha Solteira, 2001.

O S. papillosus foi o primeiro nematódeo a ser observado nos exames coprológicos dos cordeiros, de ambos os grupos, a partir da $1^{\text {a }}$ faixa etária. Observou-se que para os animais do T1, o OPG de S. papillosus foi inferior ao dos animais do T2 (Figura $2)$, embora sem diferença significativa $(\mathrm{p}<0,05)$. Entretanto, para o efeito da faixa etária houve diferença significativa $(\mathrm{p}<0,01)$.

Nos animais do T1 o $S$. papillosus atingiu um pico na $3^{\mathrm{a}}$ faixa etária (OPG médio de 303,57 ), enquanto que nos animais do T2, esse pico ocorreu na $2^{\mathrm{a}}$ faixa etária, com OPG médio de 571,43 . Após esses picos, os níveis de OPG, em ambos os tratamentos, diminuíram, embora não tenham zerado, até o desmame (90 dias). Vasconcelos et al. (1985) observaram S. papillosus em $100 \%$ de ovinos, na faixa etária de 21 dias, com OPG médio de 1824; tal dado foi muito superior ao encontrado no presente trabalho. Del Carratore (2000) estudando durante um ano, o desenvolvimento de cordeiros em pastejo rotacionado e em confinamento, observou a ocorrência de $S$. papillosus nas faixas etárias mais avançadas, com o primeiro pico de infecção ao redor de 136-146 dias.

No decorrer desse experimento, o $S$. papillosus apresentou uma prevalência de $100 \%$ no T1 e $92,8 \%$ no T2, diferente do valor encontrado por Amarante et al. (1992) que foi ao redor de 36,4\% em rebanhos ovinos da região de Botucatu-SP.

Quanto à incidência dos estrongilídeos, observaram-se nos dados obtidos das coproculturas que apenas o gênero Haemonchus estava presente. Na Figura 3 observam-se os valores médios de OPG de tricostrongilideos de acordo com a faixa etária dos cordeiros, podendo-se verificar a presença desses parasitas a partir da segunda faixa etária (dois no T1 e três no T2). Segundo a metodologia adotada, cada vez que o OPG fosse igual ou maior a 1000, o cordeiro receberia o tratamento anti-helmíntico.

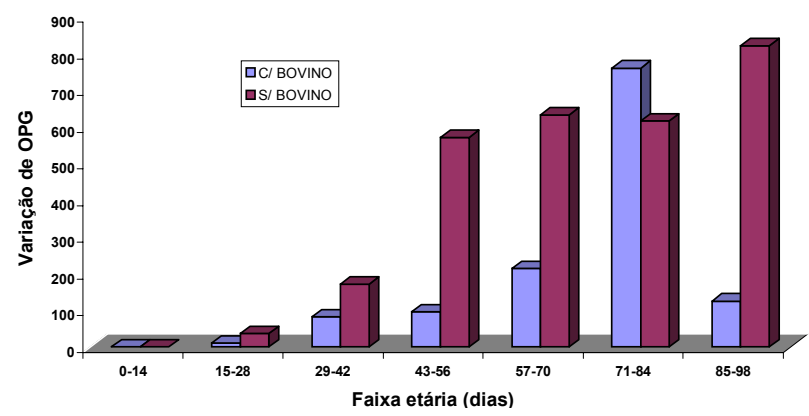

Figura 3 - Valores médios de OPG de tricostrongilídeos em cordeiros Ile de France ( $\mathrm{n}=14$ ), submetidos a pastejo rotacionado alternado com bovino e sem bovino. Ilha Solteira, 2001.

$\mathrm{Na}$ terceira faixa etária, dois cordeiros do T1 apresentaram ovos nas fezes, (sendo que um precisou de desverminação, 1150 OPG); no T2, oito 
cordeiros apresentaram OPG que variou de 50 a 700, mas nenhum animal precisou de dosificação (OPG menor que 1000). Na quarta faixa etária, cinco cordeiros do T1 apresentaram OPG (em torno de 50), mas apenas um necessitou de dosificação; e dois do T2, precisaram de desverminação (2150 OPG e 1100 OPG), embora fossem nove os que apresentaram OPG médio em torno de 350 . Na quinta faixa etária, seis cordeiros do T1 (um dosificado, com 2650 OPG) e 12 do T2 (três dosificados, com OPG médio de 2500) apresentaram ovos nas fezes. Na sexta faixa etária, 13 cordeiros do T1 (quatro dosificados, com OPG médio de 1250) e todos do T2 (apenas um dosificado, com OPG 1800) apresentaram ovos por grama de fezes em níveis consideráveis (mas abaixo de 1000). Na sétima faixa etária, foram desverminados cinco cordeiros do T2, embora todos os outros nove apresentassem OPG, que variou de 50 a 900; e um cordeiro no T1, embora houvesse 13 cordeiros com uma média de 125 OPG para tricostrongilídeos. Os cordeiros utilizados no experimento encontravam-se numa faixa etária caracterizada por alta suscetibilidade aos parasitas e com altos índices de mortalidade, que, segundo Siqueira (2001), pode atingir ao redor de $16 \%$, em criações feitas em pastejo. Além disso, esses cordeiros encontravam-se sob condições ambientais favoráveis à permanência de larvas na pastagem conforme observado por Fernandes et al. (2004), ao estudar o controle da verminose ovina em suas mães.

Através do modelo adotado para ovos por grama de fezes (OPG) de tricostrongilídeos, houve significância $(\mathrm{p}<0,01)$ para o efeito da interação tratamento $\mathrm{x}$ faixa etária no decorrer do experimento.

$\mathrm{Na}$ interação do efeito tratamento $\mathrm{x}$ faixa etária observou-se significância $(\mathrm{p}<0,01)$ na $4^{\mathrm{a}}$ e $5^{\mathrm{a}}$ faixas etárias, quando os animais estavam com idade entre 43-56 e 57-70 dias, respectivamente. Pode-se atribuir este resultado à influência dos bovinos como limpadores da pastagem, pois nessas idades os ovinos são bastante suscetíveis às infecções por tricostrongilídeo, como verificado por Rocha (2003) em Botucatu/SP, onde a 77,8\% dos cordeiros da raça Ile de France criados em pastejo, com suas mães, do nascimento ao desmame, necessitaram de medicação anti-helmíntica aos 43 dias de idade.

A diferença entre os dados nos dois tratamentos, visualizada na Figura 3, evidencia o papel controlador na descontaminação das pastagens, exercido pelos bovinos, como mencionado por Southcott e Barger (1975), que constataram que as pastagens de ovinos submetidos ao pastoreio prévio com bovinos por 6 , 12 e 24 semanas reduziram significativamente as infecções por Haemonchus. Pinheiro (1983), observou que o pastoreio alternado de ovinos com bovinos adultos apresentaram resultados melhores do que a utilização de bezerros desmamados. Fernandes et al. (2004) verificaram que a utilização do pastejo rotacionado e alternado de ovinos com bovinos adultos em períodos de 40 dias para a troca de pastagem, exerceu efeito benéfico significativo no controle da verminose ovina. Borba (1996) recomendou que áreas pastejadas somente com bovinos ou eqüinos adultos por períodos de três a quatro meses, podem assegurar baixos índices de contaminação para ovinos por períodos semelhantes. O pastejo alternado com animais adultos de diferentes espécies tem sido sugerido como uma alternativa que pode ser adotada para reduzir a contaminação da pastagem por larvas infectantes.

No presente estudo, nenhum animal apresentou sinais clínicos de verminose.

Através do modelo adotado para oocistos de Eimeria, por grama de fezes, houve significância $(\mathrm{p}<0,05)$ apenas para o efeito da faixa etária no decorrer do experimento.

Para esse parasita não se verificou, também, sinais clínicos de enfermidade, embora a infecção tenha acometido os animais em altos níveis (Figura 4). As médias de oocistos encontradas foram de 7048,47 no T1 e 5577,55 no T2. Apesar de não terem sido identificadas as espécies de Eimeria que acometeram os cordeiros neste experimento, o que se pode observar comparando o tamanho dos oocistos é que pelo menos duas delas estiveram presentes. Isso 
ficou evidente através dos picos apresentados nos dois tratamentos, pois Urqhart et al. (1990) relatam que as espécies mais patogênicas são a $E$. crandallis e E. ovinoidalis, ambas acometendo cordeiros entre quatro a sete semanas de idade, com uma infecção máxima ao redor de seis semanas. Neste experimento, os picos foram na quarta e na décima semanas no T1, e na oitava semana no T2. No T1, o número de oocistos nas fezes diminuiu após a décima segunda semana, persistindo em níveis baixos até o desmame (média de 2032,14); no T2, o número de oocistos nas fezes permaneceu alto após a oitava semana, sendo que os cordeiros foram desmamados apresentando uma média de 6767,85 . A persistência da Eimeria deveu-se ao fato de que os cordeiros foram mantidos em pastejo intensivo com ovelhas que produzem oocistos no período perinatal (URQHART et al., 1990). No presente trabalho, a administração de concentrados em cocho fixos, pode ter favorecido essa intensa contaminação com oocistos, e a associação com outros agentes infecciosos, como os nematódeos, também foram fatores determinantes na infecção por Eimeria, assim como foi observado por Lima (1991).

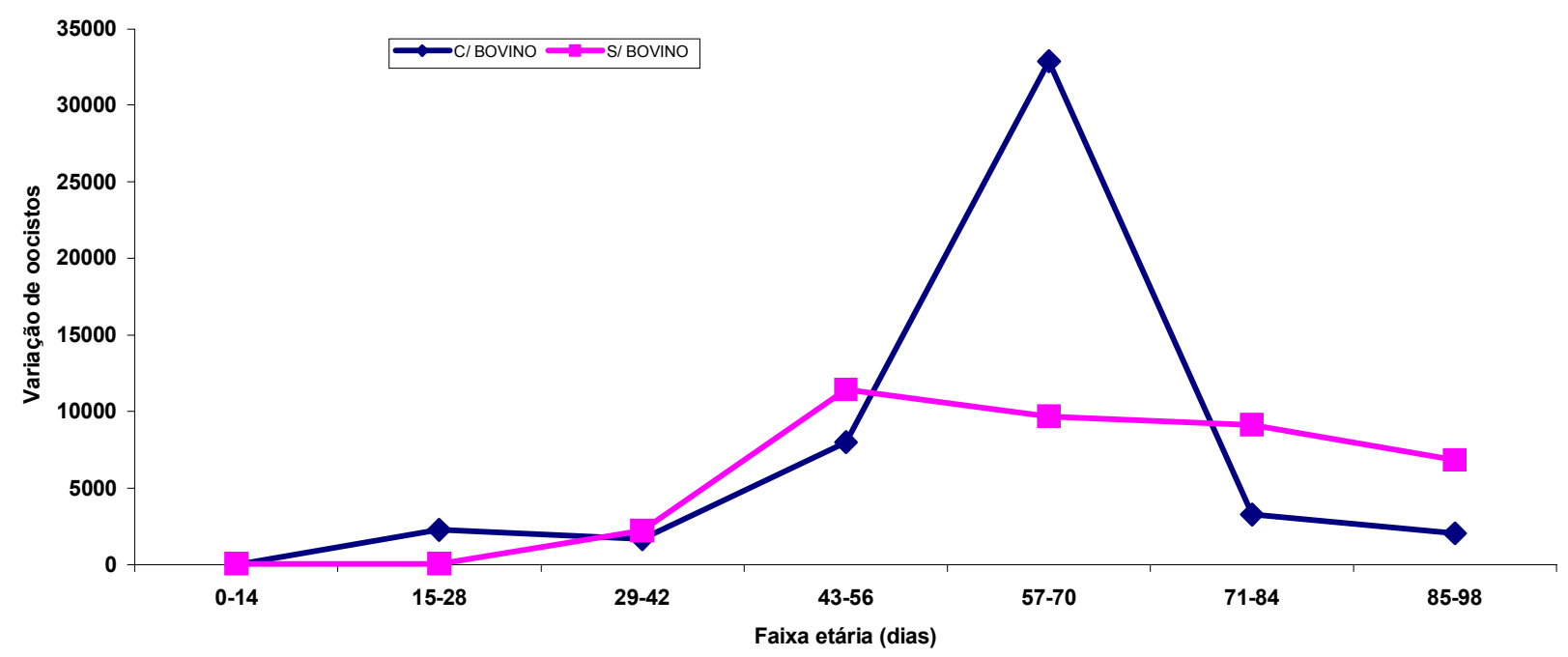

Figura 4 - Média de oocistos de Eimeria por faixa etária dos cordeiros Ile de France (n=14), submetidos a dois métodos de pastejo rotacionado, alternado com bovino e sem bovino.

Através do modelo adotado para o volume globular, houve significância $(\mathrm{p}<0,05)$ apenas para o efeito da faixa etária no decorrer do experimento.

Observou-se que os valores do VG encontrados nos animais do experimento estão dentro dos parâmetros de referência para a espécie, sem diferença significativa entre os tratamentos (Figura 5). Parâmetros de hematocrito inferiores a $20 \%$, segundo Whitlock (1958) e 24\%, segundo Jain (1986) caracterizam anemia; tal fato não foi observado neste trabalho. Os valores médios de VG foram $37,8 \%$ no $\mathrm{T} 1$, e $36,7 \%$ no $\mathrm{T} 2$. 


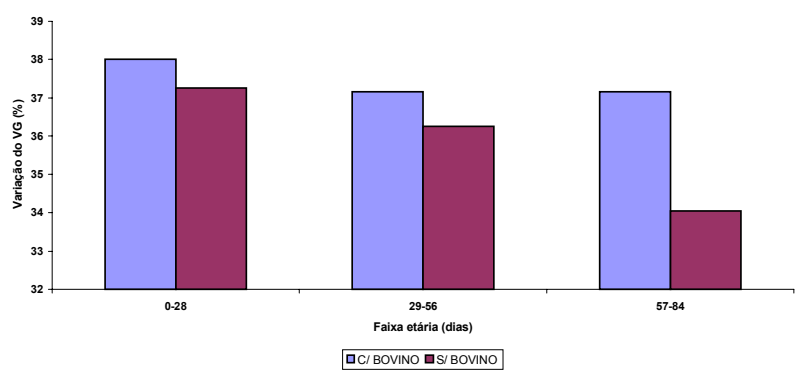

Figura 5 - Média de oocistos de Eimeria por faixa etária dos cordeiros Ile de France ( $n=14)$, submetidos a dois métodos de pastejo rotacionado, alternado com bovino e sem bovino.

O volume globular apresenta uma relação inversa com a contagem de ovos por grama de fezes (KUTTLER; MARBLE, 1960). No presente trabalho, observou-se que ocorreu queda no valor do VG ao longo do experimento nos dois métodos de pastejo rotacionado. No entanto, tais valores não chegaram a ser baixo, apesar do parasitismo por tricostrongilídeos do gênero Haemonchus no T1 e no T2.

Através do modelo adotado para o desenvolvimento ponderal, houve significância $(p<0,01)$ apenas para o efeito da faixa etária no decorrer do experimento.

A média de peso ao nascer dos 14 cordeiros do $\mathrm{T} 1$ foi de $3,25 \mathrm{~kg}$ e a do T2 foi de 3,36 kg. As médias de peso ao nascer por faixa etária estão representadas na
Figura 6. Os cordeiros foram desmamados aos 90 dias de idade, apresentando médias de peso ao desmame de $31,53 \mathrm{~kg}$ no T1 e 30,00 kg no T2. Estes valores não apresentaram diferença estatisticamente significativa, mas mostraram-se superiores aos encontrados na literatura. Figueiró (1970) verificou a média de 18,5 kg de peso vivo aos 150 dias em cordeiros Corriedale. Siqueira (2001), trabalhando com cordeiros das raças Merino Australiano, Ideal e Corriedale, obtiveram médias de peso vivo de $10 \mathrm{~kg}$, com desmame aos 60 dias. Oliveira et al. (2001) desmamaram cordeiros Santa Inês, com $23 \mathrm{~kg}$, aos 90 dias de idade, criados em pastagem; esses animais atingiram peso de abate (32 $\mathrm{kg}$ ) aos 178 dias de idade, com um ganho de peso diário de 95 g. Del Carratore (2000), comparou o desenvolvimento de cordeiros da raça Suffolk, criados em regime de pastejo (um módulo) e confinados (outro módulo), ambos até o desmame, aos 90 dias, e observou médias de 20,0 kg para os do pastejo rotacionado, e $21,0 \mathrm{~kg}$ para os cordeiros no confinamento. A média de ganho de peso diário foi de aproximadamente $0,288 \mathrm{~kg}$ para os animais do T1 (pastejo rotacionado, alternado com bovino) e $0,272 \mathrm{~kg}$ para os cordeiros do T2 (pastejo rotacionado, sem bovino). O uso de suplementação pelo sistema de "creep-feeding", provavelmente refletiu no bom desenvolvimento ponderal dos cordeiros e, conseqüentemente, no peso ao desmame, aos 90 dias de idade.

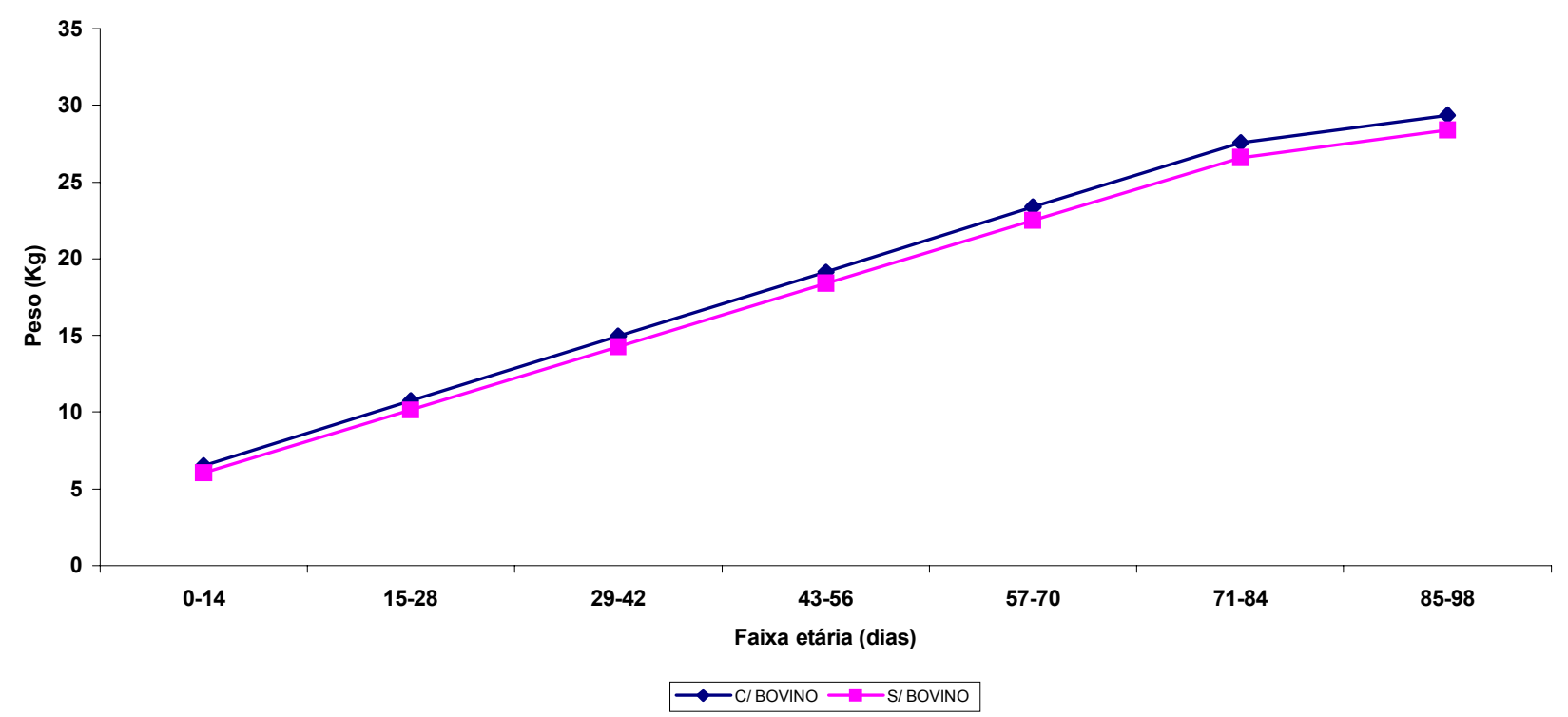

Figura 6 - Valores dos pesos médios $(\mathrm{kg})$ dos cordeiros Ile de France $(\mathrm{n}=14)$, submetidos ao pastejo rotacionado alternado com bovino e sem bovino. 
Portanto, os cordeiros do presente experimento, chegaram ao desmame aos 90 dias, com excelentes resultados em desenvolvimento ponderal, mesmo os do T2 (sem bovino), que foram desafiados pelos parasitas 1,57 vezes mais que os do T1.

De acordo com os resultados obtidos no presente experimento, concluiu-se que:

O uso do método de pastejo rotacionado e alternado com bovino adulto para a criação de cordeiros, do nascimento ao desmame (90 dias), não influenciou significativamente as endoparasitoses causadas por Strongyloides papillosus e Eimeria spp. No entanto, este método exerceu um controle significativo sobre os tricostrongilídeos, representados pelo gênero Haemonchus, nas faixas etárias de 4356 dias e 57-70 dias, reduzindo a contagem de ovos e o número de tratamentos anti-helmínticos.

O uso do pastejo rotacionado alternado ou não com bovino adulto, não influenciou no desenvolvimento ponderal e no volume globular (VG) dos cordeiros, do nascimento ao desmame.

\section{Referência}

AGRICULTURAL AND FOOD RESEARCH COUNCIL Energy and protein requirement of ruminants. Wallingford: CAB Internacional, $1993.159 \mathrm{p}$.

AMARANTE, A. F. T.; BARBOSA, M. A.; OLIVEIRA, M. A. G.; CARMELLO, M. J.; PADOVANI, C. R. Efeito da administração de oxfendazol, ivermectina e levamisol sobre os exames coproparasitológicos de ovinos. Brazilian Journal of Veterinary Research and Animal Science, São Paulo, v. 29, p. 31-38, 1992.

AMARANTE, A. F. T.; BARBOSA, M. A. Seasonal variations in populations of infective larvae on pasture and nematode fecal egg output in sheep. Veterinária e Zootecnia, São Paulo, v. 7, p. 127-133, 1995.

AMARANTE, A. F. T. Controle de endoparasitoses dos ovinos. In: REUNIÃO ANUAL DA SOCIEDADE BRASILEIRA DE ZOOTECNIA, 38., Piracicaba. Anais...Piracicaba, 2001, p. 461-471.

BAGNOLA JÚNIOR, J.; AMARANTE, A. F. T.; MEYER, L. F. F. Verminose em eqüinos: exames parasitológicos, contaminação da pastagem e pastejo alternado com ovinos. Veterinária e Zootecnia, São Paulo, v. 8, p. 47-57, 1996.
BAERMANN, G. Eine einfache methode zur auffindung von ankylotonum (nematoden) larven in erdproben. Medical Journal For The Netherlands Indies, Batavia, v. 57,p. 131-137, 1917.

BORBA, M. F. S. Efeitos do parasitismo gastrintestinal sobre o metabolismo do hospedeiro. In: SILVA SOBRINHO, A. G. (Ed.) Nutrição de ovinos. Jaboticabal: FUNEP, 1996. p. 213-240.

DEL CARRATORE, R. R. Avaliação do desenvolvimento ponderal, da infecção helmíntica e da viabilidade econômica de dois sistemas de terminação de cordeiros Suffolk. . 2000. 48 p. Dissertação (Mestrado) - Faculdade de Engenharia de Ilha Solteira, UNESP, Ilha Solteira, 2000.

ECHEVARRIA, F. A. M. Doenças parasitárias de ovinos e seu controle. In: SIMPÓSIO PARANAENSE DE OVINOCULTURA, 3., 1986, Guarapuava. Anais... Guarapuava, 1986. p. 46-52.

FERREIRA NETO, J. M.; VIANA, E. D.; MAGALHÃES, L. M. Patologia Clínica Veterinária. Belo Horizonte: Rabelo e Brasil, 1978. 293 p.

FERNANDES, L. H.;.SENO, M. C. Z., AMARANTE, A. F. T., SOUZA, H., BELLUZZO, C. E. C. Efeito do pastejo rotacionado e alternado com bovinos adultos no controle da verminose em ovelhas. Arquivo brasileiro de Medicina Veterinária e Zootecnia, Belo Horizonte, v. 56, n. 6, p. 733-740, 2004.

FIGUEIRÓ, P. R. P. Produção de cordeiros para abate. Revista de Medicina Veterinária, Sobral, v. 5, p. 260-266, 1970.

GORDON, H. M.; WHITLOCK, H. V. A new technique for counting nematode eggs in sheep faeces. Journal of the Council for Scientific and Industrial Research, Melbourne, v. 12, p. 50-52, 1939.

GREENHOUSE, S. W.; GEISSER, S. On methods in the analysis of profile data. Psychometrika, Williamsburg,, v. 24, n. 2, p. 95-112, 1959.

HUYNH, H.; FELDT, L. S. Conditions under which mean square ratios in repeated measures designs have exact Fdistributions. Journal of the American Statistical Association, Washington, v. 65, p. 1582-1589, 1970.

JAIN, N. C. Schalm's Veterinary Hematology. 4.ed. Philadelphia: Lea e Febiger, 1986. 1221 p.

KEITH, R. K. The differentiation of the infective larvae of some common nematode parasites of cattle. Australian Journal of Zoology, Victoria, v. 1, n. 2, p. 223-235, 1953.

KUTTLER, K. L.; MARBLE, D. W. Serum protein changes in lambs with naturally acquired nematode infections. American Journal of Veterinary Research, Chicago, v. 21, p. 445-448, 1960. 
LIMA, J. D. Eimeriose caprina. Caderno Técnico da Escola de Veterinária da UFMG, Belo Horizonte, n. 6, p. 20-28, 1991.

MACEDO, F. A. F.; MARTINS, E. N.; SIQUEIRA, E. R. ; MACEDO, V. P. Cruzamentos e sistemas de terminação na produção de carne de ovinos. In: REUNIÃO ANUAL DA SOCIEDADE BRASILEIRA DE ZOOTECNIA, 34., 1997, Juiz de Fora. Anais... Juiz de Fora, 1997. p.388-390.

OLIVEIRA, M. E.; ALENCAR, A. L. G.; NASCIMENTO, M. P. S. C. B.; SOUSA JUNIOR, A.; LOPES, J. B.; VIANA, G. E. N. Recria e terminação de ovinos em pastagem Cynodon spp. CV. Tyfton-85. In: REUNIÃO ANUAL DA SOCIEDADE BRASILEIRA DE ZOOTECNIA, 38., 2001, Piracicaba. Anais... Piracicaba, 2001. v. 2, p. 1051-52.

PINHEIRO, A. C. Verminose ovina. Hora Veterinária, Porto Alegre, n. 12, p. 5-9, 1983.

PINHEIRO, A. C.; ECHEVARRIA, F. A. M; ALVESBRANCO, F. P. J. Descontaminação da pastagem de ovinos pelo pastoreio alternado com bovino. Bagé: EMBRAPA/CNPO, 1983. 3 p. (Documentos, 3).

ROBERTS, F. H. S.; O'SULLIVAN, P. J. Methods for egg counts and larval cultures for strongyles infesting the gastro-intestinal tract of cattle. Australian Journal Agricultural Research, Victoria, v. 1, p. 99-103, 1949.
ROCHA, R. A. Resistência de ovelhas e de cordeiros das raças Santa Inês e Ile de France às infecções por nematódeos gastrintestinais. 2003, 78 p. Dissertação (Mestrado) - Faculdade de Medicina Veterinária e Zootecnia, Campus de Botucatu, UNESP, Botucatu, 2003.

SIQUEIRA, E. R. Manejo de matrizes em rebanhos produtores de carne. In: REUNIÃO ANUAL DA SOCIEDADE BRASILEIRA DE ZOOTECNIA, 38., 2001, Piracicaba. Anais... Piracicaba, 2001. v. 2, p. 447-453.

SOUTHCOTT, W. H.; BARGER, I. A. Decontamination of sheep and cattle pastures by varying periods of grazing with the alternate host. International Journal Parasitology, Elmsford, v. 5, p. 45-48, 1975.

URQHART, G. M.; ARMOUR, J.; DUNCAN, J. L.; DUNN, A. M.; JENNINGS, F. W. Parasitologia Veterinária. Rio de Janeiro: Guanabara Koogan, 1990. 306 p.

VASCONCELOS, O. T.; ROCHA, U. F.; COSTA, A. J.; MACHADO, A. M. Parâmetros parasitológicos coprológicos e necroscópicos em ovinos do município de Catanduva, Estado de São Paulo. Ars Veterinária, Jaboticabal, v. 1, p. 89-101, 1985.

WHITLOCK, J. H. The inheritance of resistence to trichostrongylidosis in sheep. I Demonstration of the validity of the phenomena. Cornell Veterinarian, Ithaca, v. 48, p. 127-133, 1958. 